\title{
Stroke volume and cardiac output non-invasive monitoring based on brachial oscillometry-derived pulse contour analysis: Explanatory variables and reference intervals throughout life (3-88 years)
}

\author{
Yanina Zócalo ${ }^{1}$, Victoria García-Espinosa ${ }^{1}$, Juan M. Castro ${ }^{1}$, Agustina Zinoveev ${ }^{1}$, \\ Mariana Marin ${ }^{1}$, Pedro Chiesa ${ }^{2}$, Alejandro Díaz ${ }^{3}$, Daniel Bia ${ }^{1}$ \\ ${ }^{1}$ Departamento de Fisiología, Facultad de Medicina, Centro Universitario de Investigación, \\ Innovación y Diagnóstico Arterial (CUiiDARTE), Universidad de la República, Montevideo, Uruguay \\ ${ }^{2}$ Servicio de Cardiología Pediátrica, Centro Hospitalario Pereira-Rossell, \\ ASSE - Facultad de Medicina, Universidad de la República, Montevideo, Uruguay \\ ${ }^{3}$ Instituto de Investigación en Ciencias de la Salud, UNICEN, CCT-Tandil, CONICET, Argentina
}

\begin{abstract}
Background: Non-invasive assessment of stroke volume (SV), cardiac output (CO) and cardiac index (CI) has shown to be useful for the evaluation, diagnosis and/or management of different clinical conditions. Through pulse contour analysis (PCA) cuff-based oscillometric devices would enable obtaining ambulatory operator-independent non-invasive hemodynamic monitoring. There are no reference intervals (RIs), when considered as a continuum in childhood, adolescence and adult life, for PCA-derived $S V[S V(P C A)], C O[C O(P C A)]$ and $C I[C I(P C A)]$. The aim of the study were to analyze the associations of $S V(P C A), C O(P C A)$ and $C I(P C A)$ with demographic, anthropometric, cardiovascular risk factors (CVRFs) and hemodynamic parameters, and to define RIs and percentile curves for SV(PCA), $C O(P C A)$ and $C I(P C A)$, considering the variables that should be considered when expressing them.

Methods: In 1449 healthy subjects (3-88 years) SV(PCA), CO(PCA) and CI(PCA) were non-invasively obtained (Mobil-O-Graph; Germany). Analysis: associations between subject characteristics and $S V(P C A), C O(P C A)$ and CI(PCA) levels (correlations; regression models); RIs and percentiles for $S V(P C A), C O(P C A)$ and $C I(P C A)$ (parametric methods; fractional polynomials).

Results: Sex, age, and heart rate would be explanatory variables for SV, CO, and CI levels. SV levels were also examined by body height, while body surface area (BSA) contributing to evaluation of CO and CI. CVRFs exposure did not contribute to independently explain the values of the dependent variables. SV, CO and CI levels were partially explained by the oscillometric-derived signal quality. RIs and percentiles were defined.

Conclusions: Reference intervals and percentile for SV(PCA), $C O(P C A)$ and $C I(P C A)$, were defined for subjects from 3-88 years of age, results are expressed according to sex, age, heart rate, body height and/or BSA. (Cardiol J 2021; 28, 6: 864-878)
\end{abstract}

Key words: adolescents, adults, cardiac output, children, pulse contour analysis, reference intervals

Address for correspondence: Dr. Yanina Zócalo, MD, PhD, Physiology Department, School of Medicine, Centro Universitario de Investigación, Innovación y Diagnóstico Arterial (CUiiDARTE), Universidad de la República, General Flores 2125, 11800 Montevideo, Uruguay, tel/fax: 0598-29293414-3313, e-mail: yana@fmed.edu.uy; cuiidarte@fmed.edu.uy

Received: 4.07.2019 Accepted: 15.10.2019 Early publication date: 11.03 .2020

This article is available in open access under Creative Common Attribution-Non-Commercial-No Derivatives 4.0 International (CC BY-NC-ND 4.0) license, allowing to download articles and share them with others as long as they credit the authors and the publisher, but without permission to change them in any way or use them commercially. 


\section{Introduction}

Non-invasive assessment of left ventricle stroke volume (SV), cardiac output (CO) and cardiac index (CI) were shown to be useful for the evaluation, diagnosis and/or management of different clinical and physiological conditions in both pediatric, and adult populations $[1,2]$. Several non-invasive and/or minimally invasive approaches have been proposed to determine SV, $\mathrm{CO}$ and $\mathrm{CI}$ (i.e. transpulmonary-thermodilution, thoracic bioimpedance-bioreactance, ultrasonography). Among them, echocardiography stands out as a method widely used and recommended in clinical practice [3-5]. However, different factors contribute to circumscribe the use of echocardiography to certain contexts and conditions, limiting its widespread use (i.e. for community-based epidemiological studies). Among those factors are: (1) physical (size) restrictions and cost of the devices, (2) operator-dependency and the need for a learning-curve, (3) inability to obtain adequate records in many subjects or conditions, (4) different acquisition approaches may affect measurement variability, (5) a relatively long period of time is required to complete a study and/or (6) ambulatory records or continuous monitoring of the variables cannot be obtained $[6,7]$. Pulse contour analysis (PCA) of blood pressure (BP) waveforms obtained non-invasively would enable estimating the SV, CO and CI [8-12]. Among the different approaches and devices available, the cuff-based oscillometric devices would be of choice, in cases of population studies within a community, taking into account their portability, high speed of measurement (2-3 $\mathrm{min}$ ), operator-independence and need for minimal collaboration of the subject (e.g. children) [13-15].

In both, pediatric and adult populations, there is scarce data about normal and reference values for SV, CO and CI at rest. That is particularly true for data obtained from PCA. Furthermore, available information acquired in specific (i.e. Asian) populations cannot not be extrapolated to other populations $[16,17]$. The present group of researchers have been working on the identification and definition of particular characteristics (i.e. age-related changes, percentile curves, reference intervals [RIs]) of cardiovascular variables in several populations; with special emphasis which considers childhood, adolescence and/or adult life as a continuum [18-23].

The main aims herein, were to analyze the associations of SV(PCA), CO(PCA) and CI(PCA) with demographic, anthropometric, cardiovascular risk factors (CVRFs) and hemodynamic parameters, and to define percentile curves and RIs for SV(PCA), $\mathrm{CO}(\mathrm{PCA})$ and $\mathrm{CI}(\mathrm{PCA})$, taking into account the variables that should be considered when expressing them (e.g. age, sex, body surface area [BSA]).

\section{Methods}

Healthy subjects ( $n=1449 ; 3-88$ years) from the community were considered for enrolment (Table 1) [18-22]. Hypertension, diabetes or dyslipidemia were considered present if the subject reported being in treatment and/or a previous diagnosis of their condition. Subjects were classified as sedentary when the physical activity they performed was lower than a moderate intensity of physical load. Smoking at least one cigarette per week was defined as a current smoker. Family history of cardiovascular disease was defined by the presence of first-degree relatives with premature cardiovascular disease [18-22]. Body mass index (BMI) was calculated as the weight-to-squared height ratio converted into percentiles/z-scores (subjects $<18$ years) [18-22].

\section{Pulse contour analysis}

Readings were obtained after $10 \mathrm{~min}$ of rest. The oscillometric-cuff (Mobil-O-Graph; I.E.M.-GmbH, Germany) was placed on the left arm. The device measured peripheral (brachial) mean $\mathrm{BP}(\mathrm{MBP})$ and determined peripheral systolic BP, diastolic $\mathrm{BP}$ and pulse pressure (pSBP, $\mathrm{pDBP}, \mathrm{pPP}$ ). Peripheral waveforms were calibrated to $\mathrm{pDBP}$ and calculated MBP $(\mathrm{MBP}=\mathrm{pDBP}+\mathrm{pPP} / 3)$. From the peripheral measurements, the Mobil-O-Graph determined the central (aortic) BP waveform and quantified [14, 15]: (1) central systolic BP, diastolic $\mathrm{BP}$ and pulse pressure (cSBP, cDBP, cPP); (2) heart rate (HR); (3) pulse wave analysis (PWA)-derived parameters like $\mathrm{P} 1$ and $\mathrm{P} 2$, augmented pressure (AP), augmentation index without and with normalization to a HR = 75 beats/min (AIx, AIx@75), pulse wave velocity (PWV), forward (Pf) and backward $(\mathrm{Pb})$ wave components, reflection coefficient; (4) SV, CO, CI, and total systemic vascular resistance. Only data from accurate waves were considered. Record quality was consigned as an in-device quality index: (1 - excellent, 2 - good, and 3 - minimally acceptable record). Data assigned to each subject were an average of at least three measurements.

\section{Data analysis}

Data analysis was done using MedCalc (v.18.5, MedCalc Inc., Belgium) and IBM-SPSS Statistical 


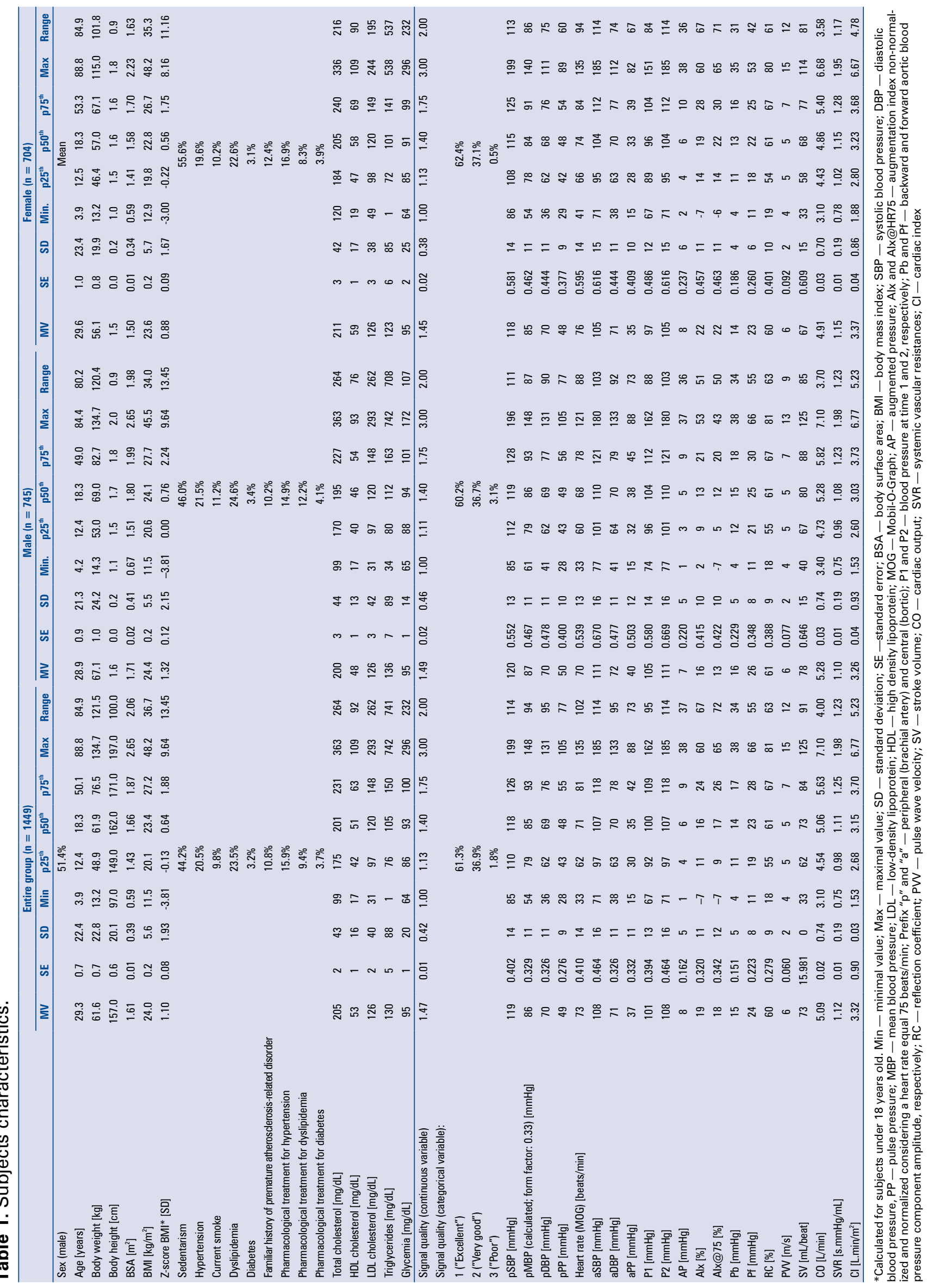


Software (v.20, SPSS Inc., USA). A p $<0.05$ was considered statistically significant.

Associations between the subject characteristics (demographic, anthropometric, CVRFs, hemodynamic characteristics) and the SV(PCA), $\mathrm{CO}(\mathrm{PCA}), \mathrm{CI}(\mathrm{PCA})$ and signal-quality index levels were evaluated. To this end, simple and pointbiserial correlations (Table 2) and multiple linear regression models (MLR, Stepwise) were considered (Table 3). After age, sex, BSA and height adjustment, there were no significant associations between the exposure to CVRFs and SV, CO or CI levels. Consequently, disregarding their exposure to CVRFs, all subjects studied could be considered in constructing the RIs.

As a result of the analysis described: (1) sex and age-specific RIs for SV(PCA), $\mathrm{CO}(\mathrm{PCA})$ and CI(PCA); (2) height specific RIs for SV(PCA) and (3) BSA specific RIs for $\mathrm{CO}$ and CI were considered necessary (Table 3 ). Then, age-related, heightrelated and BSA-related (always discriminated by sex) equations for mean and $\mathrm{SD}$ values were obtained for PCA-derived parameters. To this end, parametric regression methods based on fractional polynomials (FPs) were implemented [18-21, 24-27]. Briefly (as an example), mean and SD regression curves for age-specific SV(PCA), $\mathrm{CO}(\mathrm{PCA})$ and $\mathrm{CI}(\mathrm{PCA})$ were defined as fitting FPs. Thereafter, age-specific mean and standard deviation $(\mathrm{SD})$ values could be obtained. As an example, $\mathrm{CO}(\mathrm{PCA})$ mean equation would be: $=\mathrm{a}+\mathrm{b} \times$ age $^{\mathrm{p}}$ $+c \times$ age $^{q}+\ldots$, where $a, b$, and $c$, are coefficients, and $\mathrm{p}, \mathrm{q}$, are powers, with numbers selected from the set $[-2,-1,-0.5,0,0.5,1,2,3]$, estimated from the regression for the mean $\mathrm{CO}(\mathrm{PCA})$ curve. Continuing the example, FPs with powers [1,2], that is, with $\mathrm{p}=1$ and $\mathrm{q}=2$, illustrates an equation with the form $\mathrm{a}+\mathrm{b} \times$ age $+\mathrm{c} \times$ age $^{2}$ [24]. Residuals were used to assess the model fit, deemed appropriate if the scores were normally distributed, with a mean equal to 0 and an SD equal to 1 , randomly scattered above and below 0 when plotted against age. The best fitted curves, considering visual and mathematical criteria (Kurtosis and Skewness coefficients) were selected. From the mean and SD equations, and considering the standard normal distribution (Z) age-specific, HR-specific, heightspecific and BSA-specific percentiles were defined (SV(PCA): Fig. 1; Suppl. Tables S1-S6; CO(PCA): Fig. 2; Suppl. Tables S7-S12; CI(PCA): Fig. 3; Suppl. Tables S13-S18). The $1^{\text {th }}, 2.5^{\text {th }}, 5^{\text {th }}, 10^{\text {th }}$, $25^{\text {th }}, 50^{\text {th }}, 75^{\text {th }}, 90^{\text {th }}, 95^{\text {th }}, 97.5^{\text {th }}$, and $99^{\text {th }}$ percentile curves were calculated as mean $+\mathrm{Zp} \times \mathrm{SD}$, where $\mathrm{Zp}$ assumed $-2.3263,-1.9599,-1.6448,-1.2815$,
$-0.6755,0,0.6755,1.2815,1.6448,1.9599$, and 2.3263 values, respectively.

The minimum sample size required $(\mathrm{n}=377$ subjects) for RIs construction (i.e. for males or females) was defined considering a normal distribution for the covariate in the sample (conservatively), a $95 \%$ and $90 \%$ limit of reference and confidence interval (two-sided), respectively; with a $95 \%$ and $10 \%$ reference range and relative margin of error, respectively [18-21, 28]. According to the central limit theorem, a normal distribution was assumed considering Kurtosis and Skewness coefficients distribution and the number of subjects studied (sample size > 30) [29].

\section{Results}

\section{SV(PCA), CO(PCA), CI(PCA):}

Impact of sex, age, HR and

anthropometric characteristics

Table 1 describes characteristics of the 1449 subjects included in the study. Note the wide age range considered (3-88 years old) and the balanced sex distribution $($ male $=51.4 \%)$.

Table 3 shows explanatory variables for SV(PCA), CO(PCA) and CI(PCA) values (MLR models). The variables considered were those with statistically significant associations with PCA-derived data in bivariate analyses (Table 2). Sex, age, and HR would be explanatory variables for dependent variables (SV, CO, CI). SV levels were also explained by height, while BSA contributed to explain $\mathrm{CO}$ and CI. CVRFs did not contribute to explain, independently, the values of the dependent variables. Then, data from all the studied subjects could be considered for the RIs, which should be sex-specific and expressed taking into account age, HR and height or BSA) (Table 3). It is noteworthy that variations in SV, CO and CI were partially explained by the oscillometric-derived signal quality. A higher signal quality was associated with higher SV, CO and CI (Tables 2, 3).

\section{SV(PCA), CO(PCA), CI(PCA):}

Percentile curves and RIs for children, adolescents and adults

Figure 1 shows age, HR and height-specific percentile curves for SV(PCA). Supplementary Tables S1-S6 show sex-specific RIs for SV considering age, HR and height.

Age, HR and BSA-specific percentile curves for $\mathrm{CO}(\mathrm{PCA})$ and $\mathrm{CI}(\mathrm{PCA})$ in males and females are shown in Figures 2, 3. Supplementary Tables S7-S12 show sex-specific RIs for CO considering 


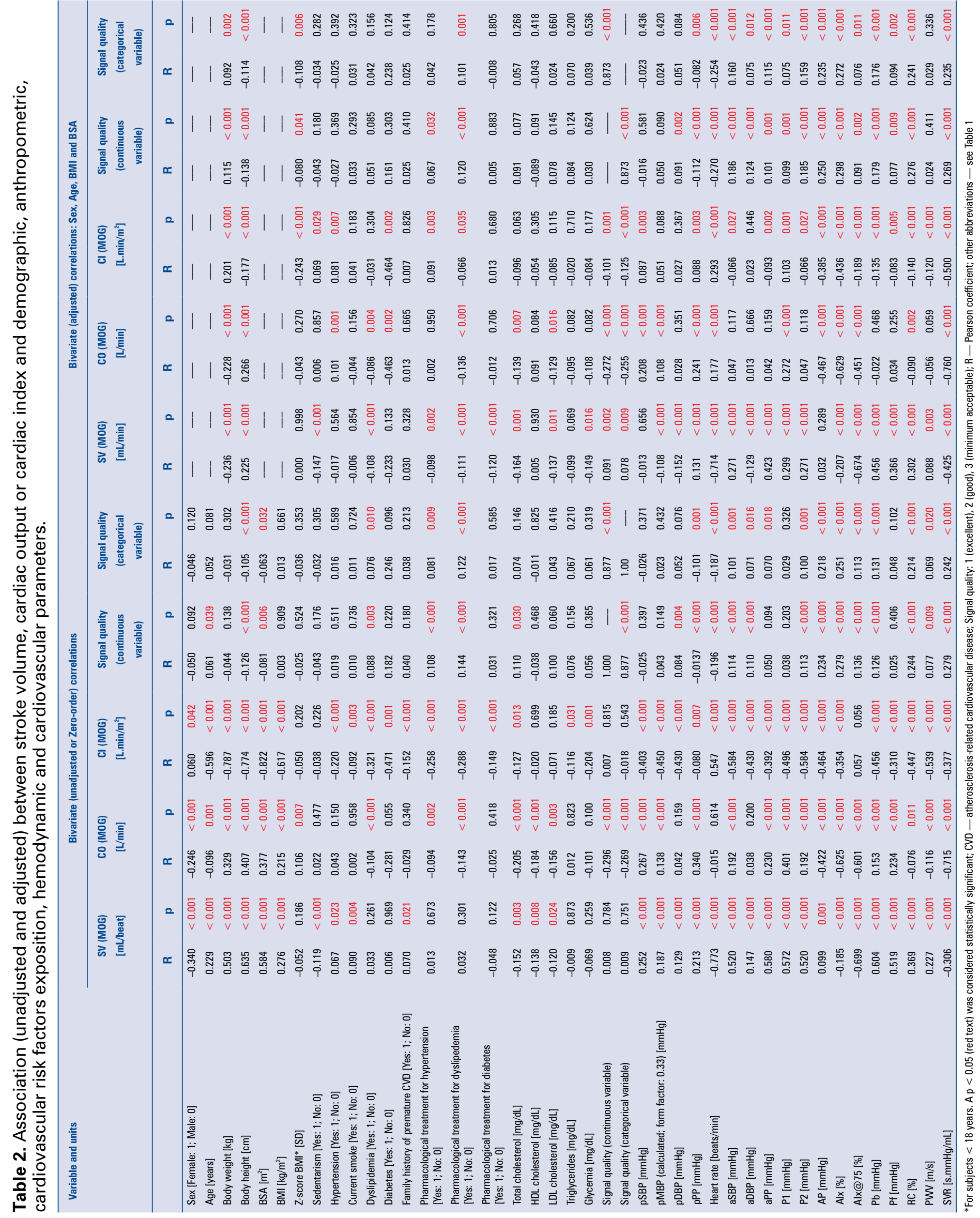




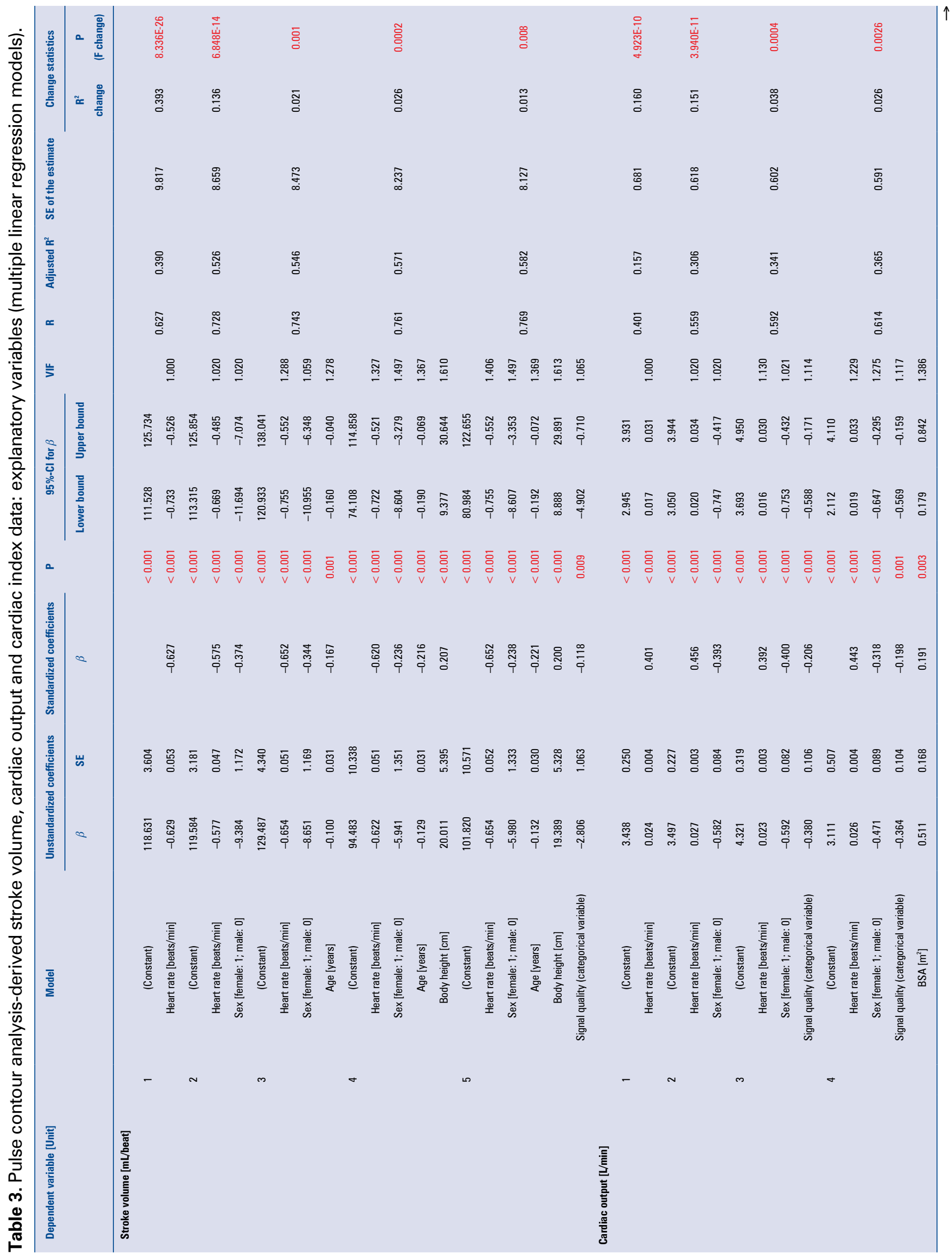




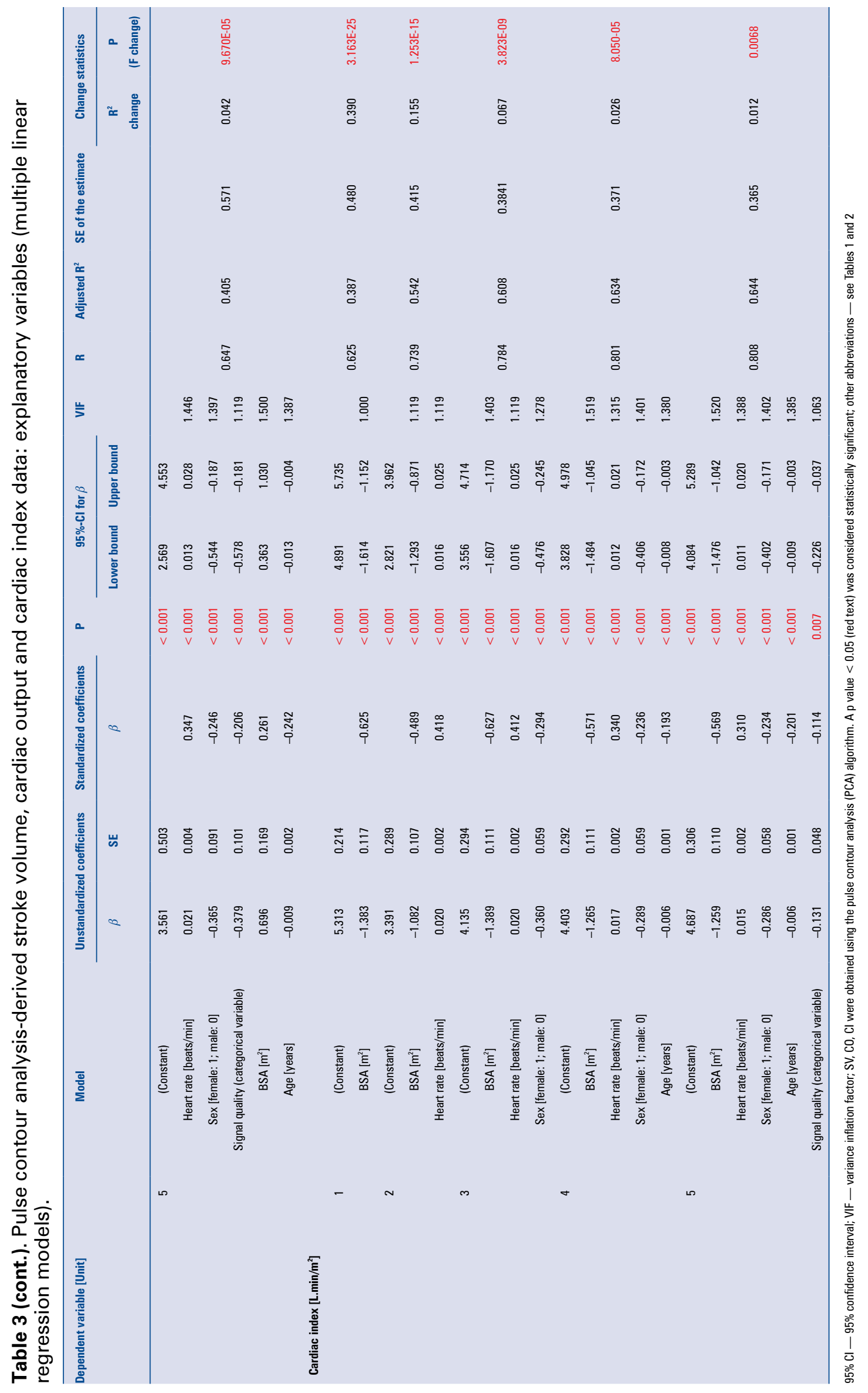




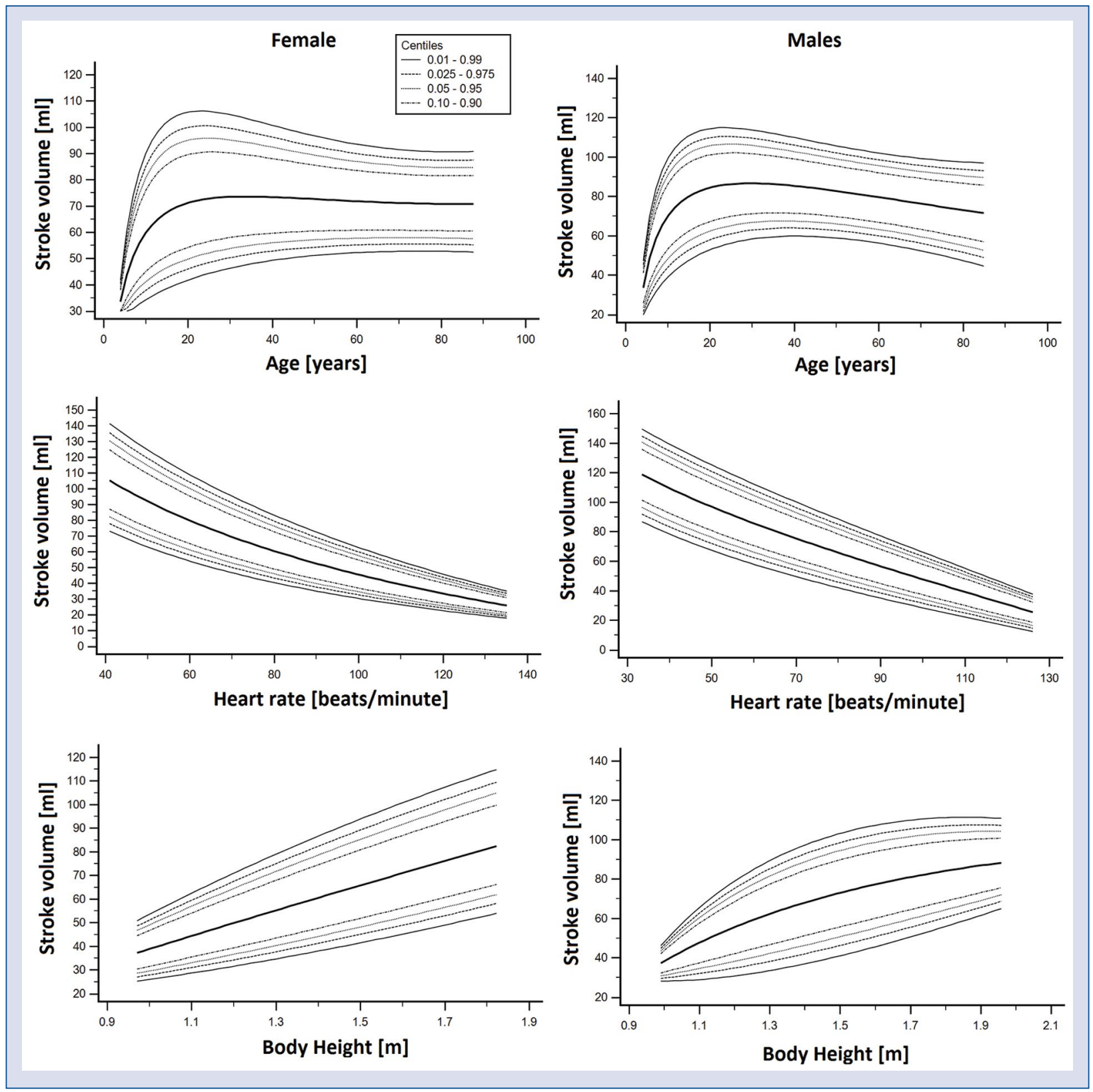

Figure 1. Age-specific, heart rate-specific and body height-specific percentiles of left ventricle stroke volume in females and males.

age, HR and BSA. Supplementary Tables S13-S18 show sex-specific RIs for CI considering age, HR and BSA.

\section{Discussion}

The work's main findings were:

- First, in the construction of RIs for PCAderived SV, CO and CI, not only were the age and anthropometric variables of the subjects taken into account, but also their sex and HR. The importance of the different explanatory variables varied depending on the parameter for which the RIs were constructed (SV, CO or CI) (Tables 2, 3).

- Second, this study represents the first study in which RIs and percentiles for PCA-derived $\mathrm{SV}, \mathrm{CO}$ and $\mathrm{CI}$ are defined for children, adolescents, adults and elderly subjects (as a continuum throughout life; 3-88 years old) (Figs. 1-3; Suppl. Tables S1-S18).

- Third, when SV levels were analyzed it a steep rise in SV was observed during the first two decades, followed by a slow decline over the 

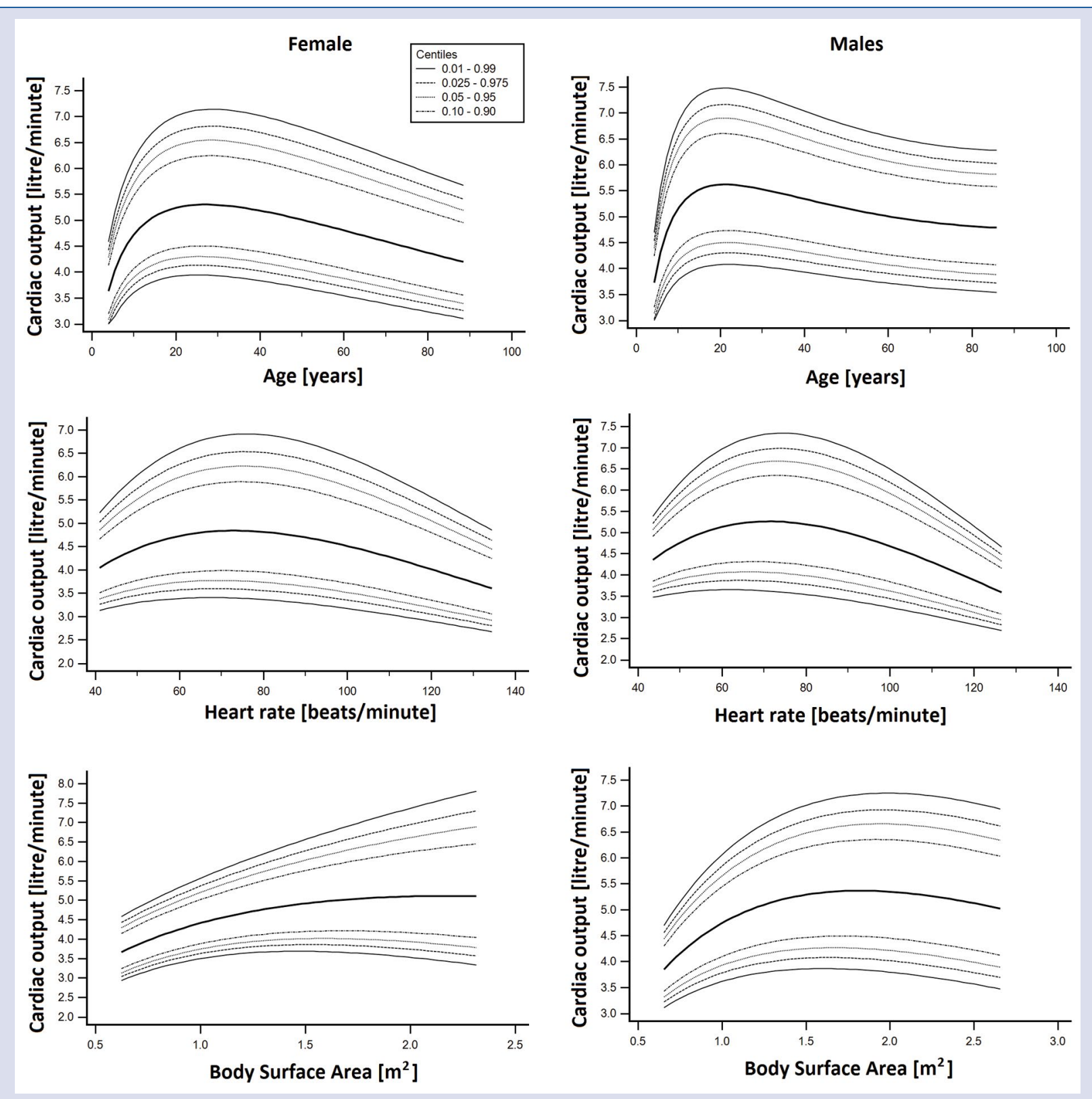

Figure 2. Age-specific, heart rate-specific and body surface area-specific percentiles of left ventricle cardiac output in females and males.

rest of their lives; additionally, the higher the $\mathrm{HR}$, the lower the SV, while the higher the height, the higher the expected SV values (Fig. 1). There was a rapid increase in $\mathrm{CO}$ in the first two decades of life, followed by a fall throughout adult life (Fig. 2). Initially CO increases as HR increases, until HR reaches $\sim 70-80$ beats $/ \mathrm{min}$, then $\mathrm{CO}$ begins to fall in association with increases in HR; additionally, $\mathrm{CO}$ increases as the BSA increases (Fig. 2). CI values showed an important fall during the first two decades and then they remained practically unchanged over the rest of their lives (Fig. 3). CI increases in association with increases in $\mathrm{HR}$, while lower CI values were observed in association with higher BSA values (Fig. 3).

The need to express SV, CO and/or CI values considering the age and/or anthropometric characteristics is widely known and accepted. However, it is of note that RIs constructed for a population including subjects from childhood to old age are scarce; in most works the age-groups included people of very different ages (i.e. 20 years apart) 


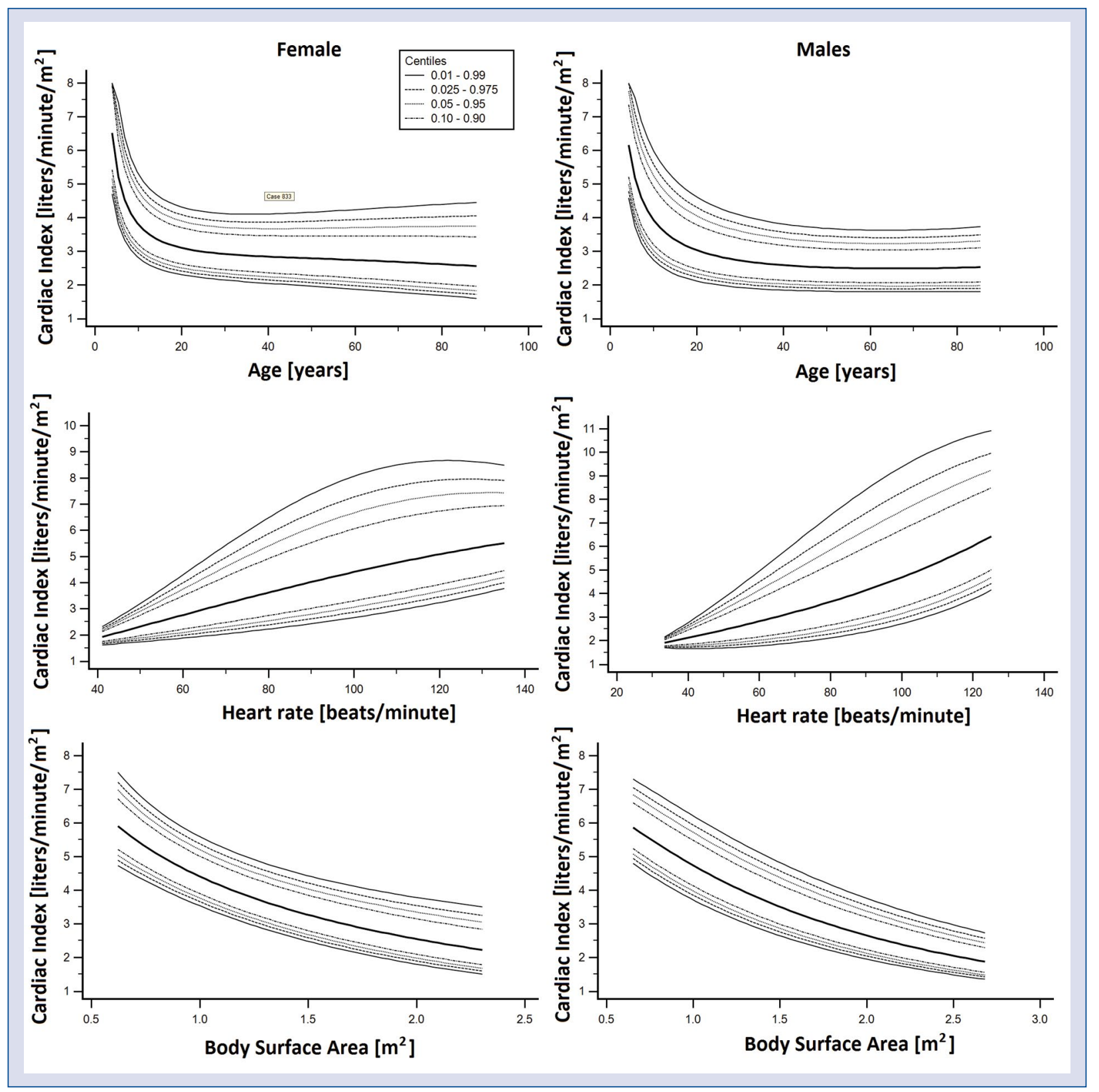

Figure 3. Age-specific, heart rate-specific and body surface area-specific percentiles of left ventricle cardiac index in females and males.

[30]; only adults were considered [5, 30, 31]; subjects aged 60-65 and older were assigned to a single group [5, 30] and/or non-uniform age ranges were considered (i.e. $0-2.9,3-5.9,6-11.9,12-17.9$, $18-29.9,30-59.9$, and $\geq 60$ years old) [32]. The above does not allow for an adequate analysis of the age impact on hemodynamic characteristic and their variations. In addition, it does not allow for the use of accurate cut-off points in clinical practice (i.e. a 31 year old would be given reference values for a group ranging from 30 to 50.9 years old) [32].
The need to define RIs for males and females separately is not universally accepted and could even be considered controversial. There are works in which it was considered necessary to define sex-specific RIs, others in which the issue was not analyzed or was evaluated inaccurately, and finally, there are works that considered negligible the sex-related differences in the RIs of hemodynamic variables [16, 32-34]. In relation to the latter, sex-specific RIs were not defined; even when sex-related differences in hemodynamic 


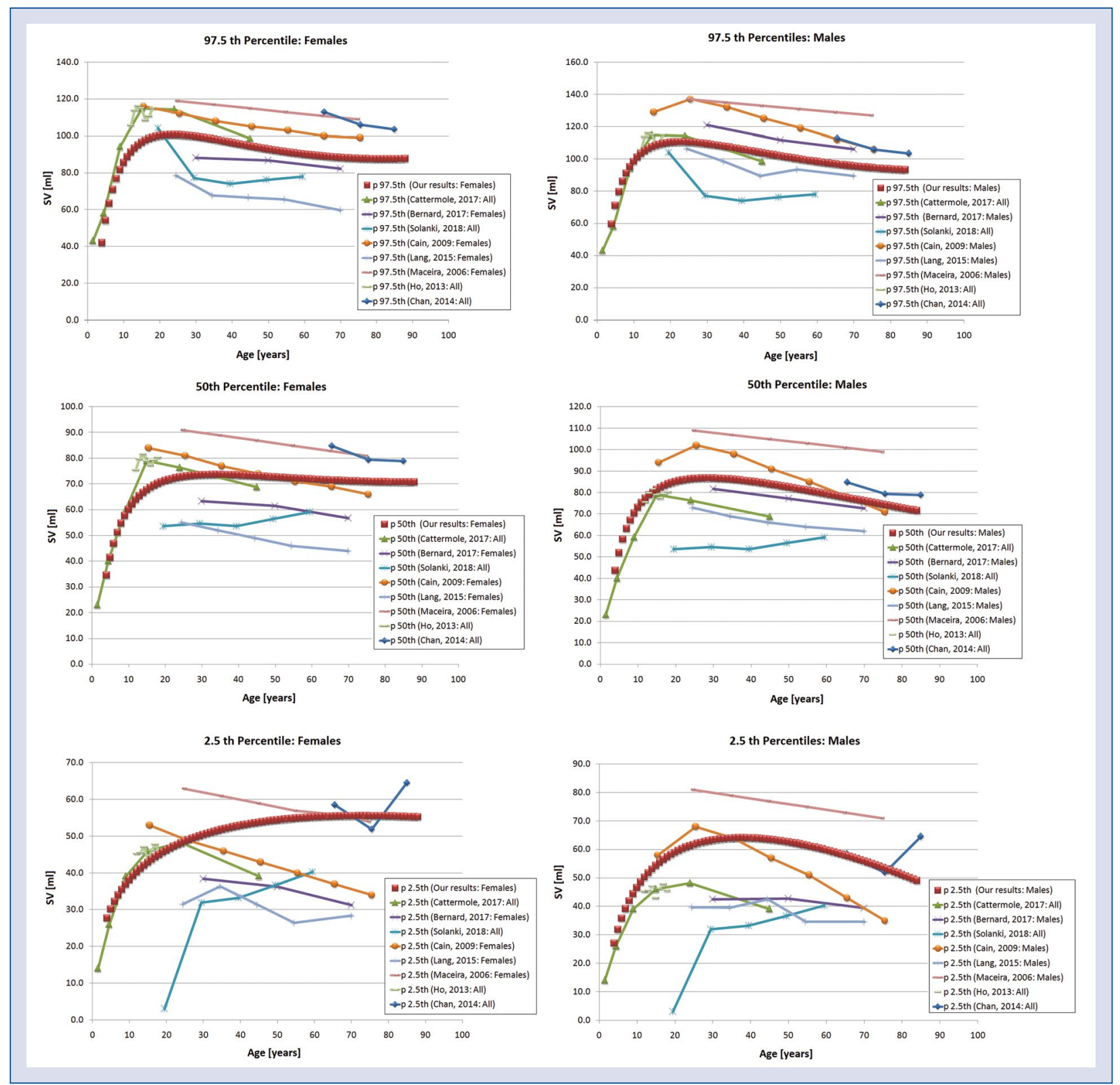

Figure 4. Age-specific percentiles $\left(97.5^{\text {th }}, 50^{\text {th }}\right.$ and $\left.2.5^{\text {th }}\right)$ of left ventricular stroke volume obtained in the present population and those reported from other authors $[5,16,30,31,32,33,34,35]$.

parameters remained statistically significant after controlling for anthropometric parameters [32]. Results herein, reinforce that the RIs in males differ for females, even after adjusting for height, weight and/or BSA (Table 3); highlighting the need for sex-specific RIs.

Finally, it is of note that oscillometric-derived signal quality was associated with SV, CO and CI values (Table 3 ). On average, a variation in the signal quality equal to the unit, could independently explain variations in SV, $\mathrm{CO}$ and $\mathrm{CI}$ equal to $2.8 \mathrm{~mL} /$ beat, $0.38 \mathrm{~L} / \mathrm{min}$ and $0.13 \mathrm{~L} / \mathrm{min} / \mathrm{m}^{2}$, respectively.
Therefore, at least in theory, further work would be necessary to identify the specific wave characteristics required and/or the minimum quality value of an aortic waveform that would allow accurate $\mathrm{CO}$ values to be obtained using PCA.

Related with our second and third main result, when RIs for SV were analyzed taking into account age-related variations, a steep rise in SV was observed during the first two decades, followed by a slow decline during the rest of life (Fig. 1). In addition, the higher the HR, the lower the SV, while the greater the height, the higher the expected SV 


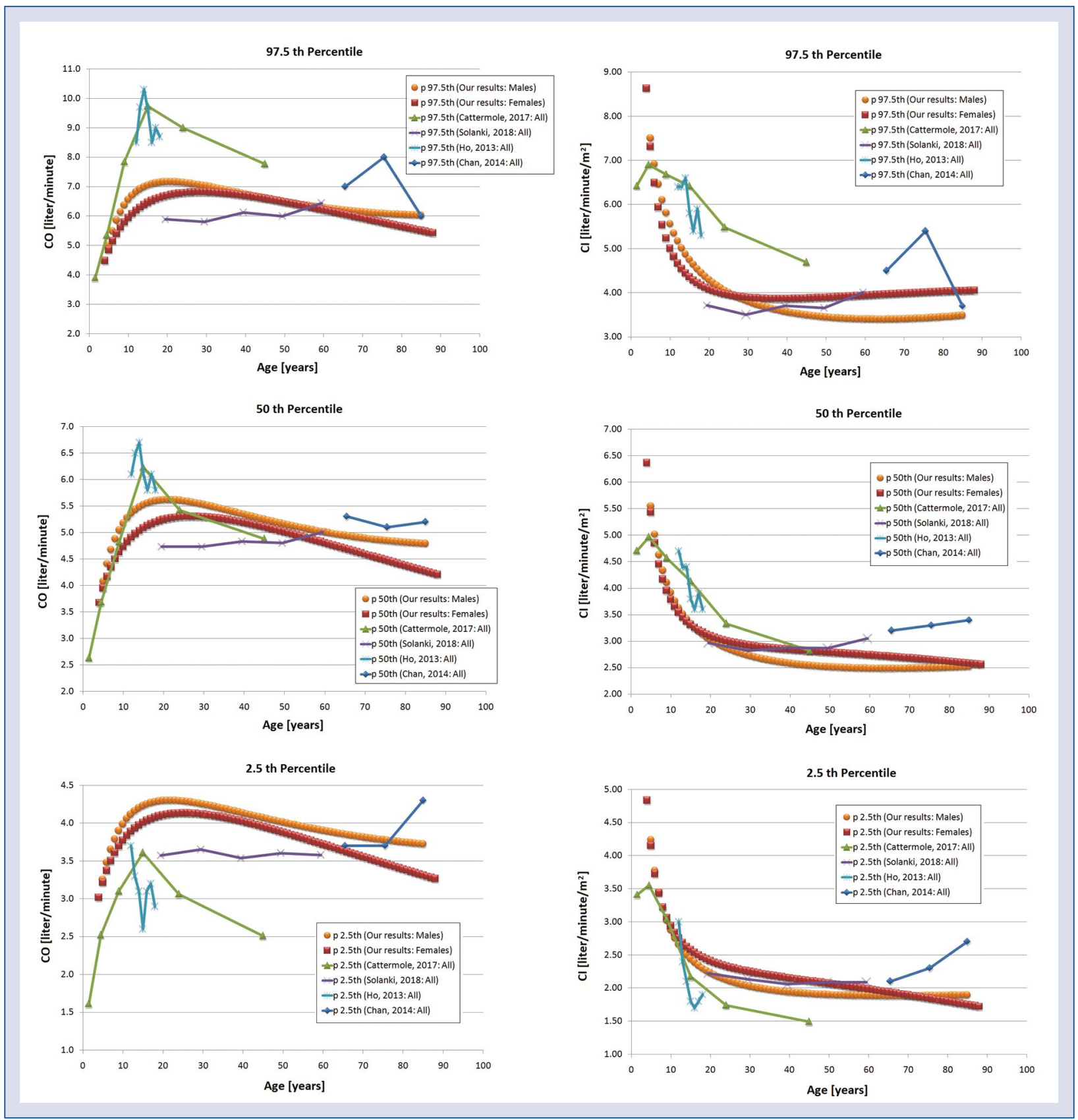

Figure 5. Age-specific percentiles $\left(97.5^{\text {th }}, 50^{\text {th }}\right.$ and $\left.2.5^{\text {th }}\right)$ of left ventricular cardiac output and cardiac index obtained in the present population and those reported from other authors [16, 32, 33, 34].

(Fig. 1). According to available research, until now there have been no reference values defined based on simultaneous or joint analysis of children, adolescents, adults or elderly subjects from a population. Since most available data correspond to values for pediatric or adult subjects it was not possible to perform direct comparisons with the present data. Therefore, a comparative analysis, from available works, an average was taken and SD values were obtained for the different ages. Then, assuming normal distribution, the $97.5^{\text {th }}$ (mean $\left.+1.96 \mathrm{SD}\right)$, $50^{\text {th }}$ (mean) and $2.5^{\text {th }}$ (mean $\left.-1.96 \mathrm{SD}\right)$ percentiles were calculated (Figs. 4, 5). Being aware of the described limitation, it could be said that similar trends were observed among other studies.

Cattermole et al. [32] in a population based, cross-sectional, observational study performed in healthy Chinese subjects ( $\mathrm{n}=2218$, age mean/ range: $16.4 / 0.5-89$ years old, $52 \%$ females), including data previously published by Ho et al. in 2013 
( $\mathrm{n}=590$, age: $12-18$ years old, $49 \%$ boys) and Chan et al. [34] in 2014 ( $\mathrm{n}=165$, age groups: $61-70$, $71-80,>80$ years old, $48.5 \%$ males), reported reference ranges for SV, $\mathrm{CO}$ and $\mathrm{CI}$ data obtained non-invasively (transcutaneous continuous Doppler) [32-34]. Despite methodological differences, including the non-uniformity of ranges used in the determination of age-subgroups and the lack of consideration of sex-related differences, in agreement with the present study the authors found a rapid increase in SV reaching its peak in their $20 \mathrm{~s}$ followed by a slow fall from the beginning of the third decade of life (Fig. 4). Time profiles and percentiles $2.5^{\text {th }}, 50^{\text {th }}$ and $97.5^{\text {th }}$ reported by Cattermole et al. [32] are similar to those presented here.

Cattermole et al. [32] is almost the only study that can be fully compared with the present results (i.e. it included a large number of subjects within a wide age range). However, they studied: (1) a small number of subjects (e.g. $n=96[31,35]$ ), (2) considered few age-groups and/or wide age intervals in the same group (i.e. 20-40, 40-60, $\geq 60$ ) [30], (3) defined sex-specific analysis as unnecessary despite the sex-related differences observed [16] and/or (4) included subjects with mild chronic illness [34], also evidenced an SV tendency which decreases with age, within the heterogeneity of the reported values. The tendency of SV (percentile $50^{\text {th }}$ ) to decrease with age was evidenced regardless of the measurement method used: three-dimensional-echocardiography [30], PCA [16], magnetic resonance [31, 35], transcutaneous continuouswave Doppler [32-34], biplane-echocardiography (Fig. 4) [5]. The rates of SV change with age (slope of association between SV $50^{\text {th }}$-percentile and age) were not very different when compared to results of other authors among themselves to the present data.

The analysis of age-related RIs for $\mathrm{CO}$ showed there was a rapid increase in $\mathrm{CO}$ levels over the first two decades of life, followed by a fall throughout adult life (in both, males and females) (Fig. 2). Initially $\mathrm{CO}$ increases as HR increases, until HR reaches $\sim 70-80$ beats $/ \mathrm{min}$, then $\mathrm{CO}$ begins to fall in association with increases in HR; $\mathrm{CO}$ increases as the BSA increases (Fig. 2).

Temporal profiles for $\mathrm{CO}$ were similar to those reported by Cattermole et al. (2017) [32]. The authors found an increase in CO, until 20 years of age. Thereafter, an age-related reduction in $\mathrm{CO}$ was observed. Cattermole et al. [32] values for the $50^{\text {th }}$-percentile and those from the present work almost overlap. In turn, Solanki et al. [16] and Chan et al. [34] reported average values $\left(50^{\text {th }}\right.$-percentile) for $\mathrm{CO}$ in adults and old age subjects similar to those found in the current data (Fig. 5).

Cardiac index values showed an important fall during the first two decades and then they remained practically unchanged (Fig. 3). CI values were associated with $\mathrm{HR}$ and BSA. CI increases in association with increases in HR, while lower CI values were observed in association with higher BSA values (Fig. 3). The described findings are in agreement with those reported by other authors (Fig. 5). In this regard, Cattermole et al. (2017) [32] and Ho et al. (2013) [33] described age-associated variations in $\mathrm{CI}$, and their $50^{\text {th }}$-percentile curves were similar to the present ones. The present curves and those reported by Solanki et al. (2018) [16] and Chan et al. (2014) [34] for the $50^{\text {th }}$-percentile in adults are comparable.

Jointly analyzing the described results, it could be stated that $\mathrm{CO}$ rises steadily and reaches a peak in the 15-20 (teenage) years of life. Thereafter, it gradually declines. However, when considering $\mathrm{CO}$ adjusted for BSA (that it is to say CI), maximum (peak) would be observed $<6$ years old, corresponding to a weight of 10-15 kg [32]. The variations in $\mathrm{CO}$ and $\mathrm{CI}$ could be related to and explained by the oxygen requirements of the tissues during those periods of life (i.e. those of maximum growth). High absolute $\mathrm{CO}$ levels in teenagers probably corresponds to accelerated growth and elevated oxygen consumption. From late teens onwards there is little or no growth, but a steadily declining level of physical activity was observed [32]. Overall, SV rises steadily until late teens then tends to decline gradually over the years, but when viewed against height (present data) or weight (Cattermole et al. data [32]), it shows a more linear positive relationship (Figs. 1, 4).

\section{Conclusions}

Sex, age, HR, and body height (for SV) or BSA (for $\mathrm{CO}$ and $\mathrm{CI}$ ) are independent factors that explain PCA-derived hemodynamic values. Consequently, when constructing RIs of SV, CO and CI, it is necessary to discriminate using these variables.

This study provides the largest database concerning RIs and percentile curves of left ventricle SV(PCA), CO(PCA) and CI(PCA), obtained in children, adolescents and adults (3-88 years of age) from Latin-America (Uruguay), expressing results according to sex (males and females), age (year-to-year), HR (beats/minute), body height (in $\mathrm{cm})$ and $\mathrm{BSA}\left(\mathrm{m}^{2}\right)$. 


\section{Ethics}

All procedures were in accordance with the ethical standards of the institutional and/or the national research committee and with the 1964 Helsinki declaration and its later amendments or comparable ethical standards. Informed consent was obtained from all individual included in the study.

\section{Acknowledgments}

This work was supported by the Agencia Nacional de Investigación e Innovación (PRSCT-008-020; FSPI_X_2015_1_108484) and by extrabudgetary funds generated by CUiiDARTE.

\section{Conflict of interest: None declared}

\section{References}

1. García X, Mateu L, Maynar J, et al. [Estimating cardiac output. Utility in the clinical practice. Available invasive and noninvasive monitoring]. Med Intensiva. 2011; 35(9): 552-561, doi: 10.1016/j.medin.2011.01.014, indexed in Pubmed: 21411188.

2. Porter TR, Shillcutt SK, Adams MS, et al. Guidelines for the use of echocardiography as a monitor for therapeutic intervention in adults: a report from the American Society of Echocardiography. J Am Soc Echocardiogr. 2015; 28(1): 40-56, doi: 10.1016/j. echo.2014.09.009, indexed in Pubmed: 25559474.

3. Majonga ED, Rehman AM, McHugh G, et al. Echocardiographic reference ranges in older children and adolescents in sub-Saharan Africa. Int J Cardiol. 2017; 248: 409-413, doi: 10.1016/j. ijcard.2017.06.109, indexed in Pubmed: 28711335.

4. Lopez L, Colan SD, Frommelt PC, et al. Recommendations for quantification methods during the performance of a pediatric echocardiogram: a report from the Pediatric Measurements Writing Group of the American Society of Echocardiography Pediatric and Congenital Heart Disease Council. J Am Soc Echocardiogr. 2010; 23(5): 465-95; quiz 576, doi: 10.1016/j.echo.2010.03.019, indexed in Pubmed: 20451803.

5. Lang R, Badano L, Mor-Avi V, et al. Recommendations for Cardiac Chamber Quantification by Echocardiography in Adults: An Update from the American Society of Echocardiography and the European Association of Cardiovascular Imaging. Eur Heart J Cardiovasc Imaging. 2015; 16(3): 233-271, doi: 10.1093/ehjci/ jev014.

6. Gottdiener JS, Bednarz J, Devereux R, et al. American Society of Echocardiography. American Society of Echocardiography recommendations for use of echocardiography in clinical trials. J Am Soc Echocardiogr. 2004; 17(10): 1086-1119, doi: 10.1016/j. echo.2004.07.013, indexed in Pubmed: 15452478.

7. Savage DD, Garrison RJ, Kannel WB, et al. Considerations in the use of echocardiography in epidemiology. The Framingham Study. Hypertension. 1987; 9(2 Pt 2): II40-II44, doi: 10.1161/01. hyp.9.2_pt_2.ii40, indexed in Pubmed: 3804399.

8. de Wilde RBP, Schreuder JJ, van den Berg PCM, et al. An evaluation of cardiac output by five arterial pulse contour techniques during cardiac surgery. Anaesthesia. 2007; 62(8): 760-768, doi: 10.1111/j.1365-2044.2007.05135.x, indexed in Pubmed: 17635422.
9. Camporota L, Beale R. Pitfalls in haemodynamic monitoring based on the arterial pressure waveform. Crit Care. 2010; 14(2): 124, doi: 10.1186/cc8845, indexed in Pubmed: 20236463.

10. Schlöglhofer T, Gilly H, Schima H. Semi-invasive measurement of cardiac output based on pulse contour: a review and analysis. Can J Anaesth. 2014; 61(5): 452-479.

11. Broch O, Bein B, Gruenewald M, et al. Accuracy of cardiac output by nine different pulse contour algorithms in cardiac surgery patients: a comparison with transpulmonary thermodilution. Biomed Res Int. 2016; 2016: 3468015, doi: 10.1155/2016/3468015, indexed in Pubmed: 28116294.

12. Grensemann J. Cardiac output monitoring by pulse contour analysis, the technical basics of less-invasive techniques. Front Med (Lausanne). 2018; 5: 64, doi: 10.3389/fmed.2018.00064, indexed in Pubmed: 29560351.

13. Weiss W, Gohlisch C, Harsch-Gladisch C, et al. Oscillometric estimation of central blood pressure: validation of the Mobil-O-Graph in comparison with the SphygmoCor device. Blood Press Monit. 2012; 17(3): 128-131, doi: 10.1097/MBP.0b013e328353ff63, indexed in Pubmed: 22561735.

14. Weber T, Wassertheurer S, Rammer M, et al. Validation of a brachial cuff-based method for estimating central systolic blood pressure. Hypertension. 2011; 58(5): 825-832, doi: 10.1161/HYPERTENSIONAHA.111.176313, indexed in Pubmed: 21911710.

15. Wassertheurer S, Kropf J, Weber T, et al. A new oscillometric method for pulse wave analysis: comparison with a common tonometric method. J Hum Hypertens. 2010; 24(8): 498-504, doi: 10.1038/jhh.2010.27, indexed in Pubmed: 20237499.

16. Solanki J, Mehta H, Shah C. Aortic blood pressure and central hemodynamics measured by noninvasive pulse wave analysis in Gujarati normotensives. Int J Clin Exp Physiol. 2018; 5(2): 75, doi: 10.4103/ijcep.ijcep_24_18.

17. Nakagomi A, Okada S, Funabashi N, et al. Age-related change in contribution of stroke volume to central pulse pressure. Clin Exp Hypertens. 2017; 39(3): 284-289, doi: 10.1080/10641963.2016.1259331, indexed in Pubmed: 28448183.

18. Díaz A, Zócalo Y, Cabrera-Fischer E, et al. Reference intervals and percentile curve for left ventricular outflow tract (LVOT), velocity time integral (VTI), and LVOT-VTI-derived hemodynamic parameters in healthy children and adolescents: Analysis of echocardiographic methods association and agreement. Echocardiography. 2018; 35(12): 2014-2034, doi: 10.1111/echo.14176, indexed in Pubmed: 30376592.

19. Díaz A, Zócalo Y, Bia D. Reference Intervals and Percentile Curves of Echocardiographic Left Ventricular Mass, Relative Wall Thickness and Ejection Fraction in Healthy Children and Adolescents. Pediatr Cardiol. 2019; 40(2): 283-301, doi: 10.1007/ s00246-018-2000-y, indexed in Pubmed: 30288599.

20. Diaz A, Zócalo Y, Bia D, et al. Reference intervals and percentiles for carotid-femoral pulse wave velocity in a healthy population aged between 9 and 87 years. J Clin Hypertens (Greenwich). 2018; 20(4): 659-671, doi: 10.1111/jch.13251, indexed in Pubmed: 29532992.

21. Díaz A, Zócalo Y, Bia D, et al. Reference intervals of aortic pulse wave velocity assessed with an oscillometric device in healthy children and adolescents from Argentina. Clin Exp Hypertens. 2019; 41(2): 101-112, doi: 10.1080/10641963.2018.1445754, indexed in Pubmed: 29521547.

22. Curcio S, García-Espinosa V, Arana M, et al. Growing-Related changes in arterial properties of healthy children, adolescents, and young adults nonexposed to cardiovascular risk factors: 
analysis of gender-related differences. Int J Hypertens. 2016; 2016: 4982676, doi: 10.1155/2016/4982676, indexed in Pubmed: 26989504.

23. Farro I, Bia D, Zócalo Y, et al. Pulse wave velocity as marker of preclinical arterial disease: reference levels in a uruguayan population considering wave detection algorithms, path lengths, aging, and blood pressure. Int J Hypertens. 2012; 2012: 169359, doi: 10.1155/2012/169359, indexed in Pubmed: 22666551.

24. Royston P, Wright E. A method for estimating age specific reference intervals ('normal ranges') based on fractional polynomials and exponential transformation. J R Statist Soc. 1998; 161(1): 79-101, doi: 10.1111/1467-985x.00091.

25. Engelen L, Ferreira I, Stehouwer CD, et al. Reference Values for Arterial Measurements Collaboration. Reference intervals for common carotid intima-media thickness measured with echotracking: relation with risk factors. Eur Heart J. 2013; 34(30): 2368-2380, doi: 10.1093/eurheartj/ehs380, indexed in Pubmed: 23186808.

26. Engelen L, Bossuyt J, Ferreira I, et al. Reference Values for Arterial Measurements Collaboration. Reference values for local arterial stiffness. Part A: carotid artery. J Hypertens. 2015; 33(10): 1981-1996, doi: 10.1097/HJH.0000000000000654, indexed in Pubmed: 26431185.

27. Bossuyt J, Engelen L, Ferreira I, et al. Reference Values for Arterial Measurements Collaboration. Reference values for local arterial stiffness. Part B: femoral artery. J Hypertens. 2015; 33(10): 1997-2009, doi: 10.1097/HJH.0000000000000655, indexed in Pubmed: 26431186.

28. Bellera CA, Hanley JA. A method is presented to plan the required sample size when estimating regression-based reference limits. J Clin Epidemiol. 2007; 60(6): 610-615, doi: 10.1016/j. jclinepi.2006.09.004, indexed in Pubmed: 17493520.
29. Lumley T, Diehr P, Emerson S, et al. The importance of the normality assumption in large public health data sets. Annu Rev Public Health. 2002; 23: 151-169, doi: 10.1146/annurev. publhealth.23.100901.140546, indexed in Pubmed: 11910059.

30. Bernard A, Addetia K, Dulgheru R, et al. 3D echocardiographic reference ranges for normal left ventricular volumes and strain: results from the EACVI NORRE study. Eur Heart J Cardiovasc Imaging. 2017; 18(4): 475-483, doi: 10.1093/ehjci/jew284, indexed in Pubmed: 28329230.

31. Maceira AM, Prasad SK, Khan M, et al. Normalized left ventricular systolic and diastolic function by steady state free precession cardiovascular magnetic resonance. J Cardiovasc Magn Reson. 2006; 8(3): 417-426, doi: 10.1080/10976640600572889, indexed in Pubmed: 16755827.

32. Cattermole G, Leung P, Ho G, et al. The normal ranges of cardiovascular parameters measured using the ultrasonic cardiac output monitor. Physiol Rep. 2017; 5(6): e13195, doi: 10.14814/ phy2.13195.

33. Ho GYL, Cattermole GN, Chan SSW, et al. Noninvasive transcutaneous Doppler ultrasound-derived hemodynamic reference ranges in Chinese adolescents. Pediatr Crit Care Med. 2013; 14(5): e225-e232, doi: 10.1097/PCC.0b013e3182772f78, indexed in Pubmed: 23439468.

34. Chan CPY, Agarwal N, Sin KK, et al. Age-specific non-invasive transcutaneous Doppler ultrasound derived haemodynamic reference ranges in elderly Chinese adults. BBA Clin. 2014; 2: 48-55, doi: 10.1016/j.bbacli.2014.09.002, indexed in Pubmed: 26672648.

35. Cain PA, Ahl R, Hedstrom E, et al. Age and gender specific normal values of left ventricular mass, volume and function for gradient echo magnetic resonance imaging: a cross sectional study. BMC Med Imaging. 2009; 9: 2, doi: 10.1186/1471-2342-9-2, indexed in Pubmed: 19159437. 